\title{
Reasons for and outcome of upper gastrointestinal endoscopy in patients aged 85 years or more: retrospective study
}

\author{
L Seinelä, J Ahvenainen, J Rönneikkö, M Haavisto
}

Upper gastrointestinal endoscopy has proved to be safe and gives a high diagnostic yield in elderly people. ${ }^{1-5}$ The prevalence of gastrointestinal diseases increases with age, and elderly people are also more vulnerable to the complications of these diseases. We retrospectively studied 154 gastroscopies performed in patients aged 85 years or more to clarify the indications for and clinical findings of gastroscopy in very old people. We also studied the influence of the examination on treatment and symptoms.

\section{Patients, methods, and results}

Between 11 October 1993 and 3 October 1996, 190 gastroscopies were performed in this department on patients aged 85 years or more. Seven patients were excluded because of failed intubation and 13 because of inadequate records. Sixteen re-endoscopies were also excluded; thus 154 gastroscopies were included in the study. The mean age of patients was 88.5 years (range 85-101). Women had 132 and men 22 examinations; this sex distribution was similar to that of all elderly patients treated in the hospital. Overall, 111 patients lived at home while the rest lived in old people's homes or were in hospital; 110 endoscopies were performed on inpatients and 44 on outpatients. Most patients had one or more chronic diseases-for example, 78 patients had ischaemic heart disease. The patients had received an average of 5 different drugs (range 0-14). To avoid hypoxia, which leads to complications in elderly people, supplemental oxygen was given and premedication, sedation, and pharyngeal lignocaine (lidocaine) spray were not used.

One indication alone seldom led to gastroscopy. The main indications were epigastric pain (83 patients), anaemia (55), vomiting (22), and nausea (20). Only two endoscopies gave normal results. The most common findings in the other 152 were gastritis, oesophagitis, and prepyloric or pyloric ulcer (table). There were no major complications related to endoscopy, and 154 efforts were successful while intubation was unsuccessful in seven patients. Endoscopy revealed the diagnosis explaining patients' symptoms in 93 of the 154 examinations. Drug treatment was changed in 119 patients, the most common change being to stop treatment with non-steroidal antiinflammatory drugs and start treatment with proton pump inhibitors.

\section{Comment}

Gastroscopy was safe and well tolerated in this study. There were no major complications, although most of the patients had one or more chronic diseases and were taking an average of five different drugs. Only seven gastroscopies were excluded because of patients' lack of cooperation, but all patients had dementia.
Normal findings were found in only two examinations, which is fewer than in previous studies. ${ }^{2-5}$ Gastroscopy revealed a diagnosis in more than half of the cases, and drug treatment was changed after $77 \%$ of the examinations. The findings were mostly amenable to drug treatment, and subjective improvement was often achieved.

All but one of the patients studied were referred for endoscopy by a doctor working in the department of geriatrics; the other was referred by her general practitioner. Over half of the patients came to the hospital as acute cases, epigastric pain, nausea, vomiting, and deterioration in the state of health being the most common reasons. Endoscopy was usually performed only after an objective finding such as anaemia or vomiting was present. In more than half of the cases the reason for acute admission was also an indication for gastroscopy.

Indications for gastroscopy for very old people should not be too strict. Gastroscopy should be regarded as a useful and safe examination in patients aged 85 years or more who have upper gastrointestinal complaints.

We thank Lauri Myllykorpi and Kirsti Nitz for correcting the grammar of the manuscript.

Contributors: $\mathrm{MH}$ had the original idea for the study and discussed the core ideas. JA participated in the study design, data collection, analyses, and writing the manuscript and performed most of the gastroscopies. JR participated in data collection and analyses and performed gastroscopies. LS initiated the study, discussed the core ideas of the study and its design, and participated in data collection, analyses, and writing the paper. LS is guarantor for the study.

Funding: None.

Conflict of interest: None.

1 Jacobsohn WZ, Levy A. Endoscopy of upper gastrointestinal tract is feasible and safe in elderly patients. Geriatrics 1977;32:80-3.

2 Lockhart SP, Schofield PM, Gribble PJN, Barron JH. Upper gastrointestinal endoscopy in the elderly. BMJ 1985;290:283.

3 Brussaard CC, Vandewoude MFJ. A prospective analysis of elective upper gastrointestinal endoscopy in the elderly. Gastrointest Endoscopy 1988;34:118-21.

4 Cooper BT, Neumann CS. Upper gastrointestinal endoscopy in patients aged 80 years or more. Age Ageing 1986;15:343-9.

5 Gibbins FJ, Collins HJ, Hall RGP, Dellipiani AW. Endoscopy in the elderly. Age Ageing 1974;3:240-4.

(Accepted 13 May 1998)

Major clinical findings at endoscopy in patients aged 85 years or more. Values are numbers (percentages) of patients. Most

patients had more than one finding

\begin{tabular}{lccc} 
Finding & Women $(\mathbf{n}=\mathbf{1 3 2})$ & Men $(\mathbf{n}=\mathbf{2 2})$ & Total \\
\hline Oesophagitis & $42(32)$ & $6(27)$ & $48(31)$ \\
\hline Hiatus hernia & $22(17)$ & $2(9)$ & $24(16)$ \\
\hline Gastritis & $91(69)$ & $12(55)$ & $103(67)$ \\
\hline Gastric ulcer & $5(4)$ & 0 & $5(3)$ \\
\hline Gastric carcinoma & $3(2)$ & $1(5)$ & $4(3)$ \\
\hline Prepyloric and pyloric ulcer & $28(21)$ & $1(5)$ & $29(19)$ \\
\hline Duodenal ulcer & $3(2)$ & $1(5)$ & $4(3)$ \\
\hline Normal & $2(2)$ & 0 & $2(1)$ \\
\hline
\end{tabular}

Department of

Geriatrics, Tampere City Hospital, Kaupin sairaala, Parantolankatu 6 FIN 33500 ,

Tampere, Finland

L Seinelä, senior physician

J Ahvenainen, deputy chief physician J Rönneikkö, senior physician M Haavisto, chief physician

Correspondence to: Dr Seinelä lllase@uta.fi

BMJ 1998;317:575 